Rabaska

Revue d'ethnologie de l'Amérique française

BOUCHARD, LORRAINE. La Mariée au grand jour. Mode, coutumes et usages au Québec 1910-1960. Montréal, Hurtubise HMH, "Cahiers du Québec " $\mathbf{n}^{0}$ 121, collection " Ethnologie », 1998, 130 p. ISBN 2-89428-310-5

\title{
Hélène Dionne
}

Numéro 1, 2003

URI : https://id.erudit.org/iderudit/201614ar

DOI : https://doi.org/10.7202/201614ar

Aller au sommaire du numéro

Éditeur(s)

Société québécoise d'ethnologie

ISSN

1703-7433 (imprimé)

1916-7350 (numérique)

Découvrir la revue

Citer ce compte rendu

Dionne, H. (2003). Compte rendu de [BOUCHARD, LORRAINE. La Mariée au grand jour. Mode, coutumes et usages au Québec 1910-1960. Montréal,

Hurtubise HMH, "Cahiers du Québec " n ${ }^{0} 121$, collection « Ethnologie ", 1998, 130 p. ISBN 2-89428-310-5]. Rabaska, (1), 159-160.

https://doi.org/10.7202/201614ar d'utilisation que vous pouvez consulter en ligne. 
Bouchard, Lorraine. La Mariée au grand jour. Mode, coutumes et usages au Québec 1910-1960. Montréal, Hurtubise HMH, "Cahiers du Québec " $\mathrm{n}^{\circ}$ 121, collection "Ethnologie ", 1998, 130 p. ISBN 2-89428-310-5.

Extrait du mémoire de maîtrise de Lorraine Bouchard, La Mariée au grand jour nous propose une revue minutieuse de tous les éléments du costume de la mariée. L'auteur a basé son étude sur un corpus d'entrevues faites auprès d'informatrices de la région de Québec et de la campagne environnante jumelée à une somme de lectures diversifiées. Les résultats de son enquête nous livrent des informations fort intéressantes sur les pratiques coutumières entourant le mariage et les règles assurant le choix du costume de la mariée sur une période de cinquante ans, de 1910 à 1960. 
Toutes les pièces du costume de la mariée y sont détaillées, qu'il s'agisse de la robe, du voile, du costume pour le voyage de noces, des souliers ou des gants en passant par tous les accessoires : la lingerie féminine, la coiffure, le maquillage ou les bijoux. Aucun élément n'a été oublié. Puis Lorraine Bouchard poursuit en inscrivant les divers éléments composant la tenue vestimentaire de la mariée dans son cadre social et familial, urbain ou rural. Elle nous introduit dans l'univers de la complicité féminine entre mère et fille, entre sœurs, belles-sœurs, cousines et amies. Elle fait aussi référence à la participation discrète mais bien réelle des pères et des fiancés.

Elle nous présente les règles de l'étiquette civile et sociale et souligne les sources d'influence que représentent les courants de la mode et l'émancipation des femmes. D'une influence déterminante, les canons de la mode dictent les choix de la jeune mariée urbaine qui se veut résolument moderne alors que la tradition et les valeurs familiales guident ceux de la future épouse en milieu rural. L'auteur nous propose deux tableaux comparatifs présentant les choix suggérés par les nouvelles tendances de la mode, et l'accueil et l'usage qui leur sont faits par les informatrices. Il est intéressant de constater l'appropriation et l'adaptation que font les futures mariées des nouveautés et de la mode selon les époques.

L'auteur poursuit son analyse en examinant l'incidence des contextes économiques et sociaux dans le choix des éléments du costume de la mariée, de même que sur le type de cérémonie et de festivités mis de l'avant pour l'organisation de la noce. Finalement, l'auteur jette un bref coup d'œil sur les coutumes, pratiques et croyances entourant le mariage.

L'étude de Lorraine Bouchard fait un joli tour de piste sur le costume de la mariée et l'organisation de cette journée que chacune veut exceptionnelle et inoubliable tout en portant la signature distinctive de la personnalité de la future épouse.

Hélène Dionne Musée de la civilisation, Québec 